\title{
AS TRÊS GRAÇAS DO MAMULENGO (A INFÂNCIA ADULTA, O JOGO E A MÚSICA)
}

\author{
THE THREE PLEASANTRY OF THE \\ MAMULENGO (THE CHILD-ADULTHOOD, \\ THE PLAY AND THE MUSIC) \\ LAS TRES GRACIAS DEL MAMULENGO \\ (LA INFANCIA ADULTA, EL JUEGO Y LA MÚSICA)
}

ANDRÉ CARRICO 


\section{RESUMO}

O objetivo deste texto é refletir acerca de procedimentos utilizados por brincantes de Teatro de Mamulengo no século XXI, para manter a atenção do público e extrair a gargalhada de dentro de uma barraca de tecido rústico e com alguns bonecos de madeira. O que torna a graça do Mamulengo eficiente? A partir de pesquisa que acompanha apresentações de bonequeiros no Estado do Rio Grande do Norte há cinco anos, nossa hipótese é a de que, entre os elementos que mantêm o Teatro de Mamulengo como gênero eficiente destacam-se uma estética e linguagem ao mesmo tempo infantil e adulta, o jogo e a música.

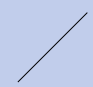

ABSTRACT

The purpose of this text is to reflect on the main procedures used by the players of Mamulengo's Theatre in the 21st century to maintain the interest of the public and to extract the laughter from a tent of rustic fabric and just with some wooden puppets. What makes efficient Mamulengo's comicity? Based on research that has followed shows from puppeteers in the State of Rio Grande do Norte since five years, Our hypothesis is that, among the elements that keeps Mamulengo's Theatre as an efficient genre stand out an aesthetic and language at the same time childish and adult, the play and the music.

\section{RESUMEN}

El objetivo de este texto es reflexionar acerca de los principales procedimientos utilizados por actores de Teatro de Mamulengo en el siglo XXI para mantener la atención del público y extraer la carcajada de dentro de una tienda de tejido rústico y con algunas marionetas de madera. ¿Qué hace que la gracia del Mamulengo sea eficiente? Basado en una investigación que ha seguido las presentaciones de los titiriteros en la Província de Rio Grande do Norte durante cinco años, nuestra hipótesis es que, entre los elementos que mantiene el Teatro de Mamulengo como género eficiente se destacan una estética y lenguaje al mismo tiempo infantil y adulta, el juego y la música.

\section{Palavras-chave:}

Cultura Popular. Teatro de Mamulengo. Infância. Jogo. Música.

\section{KEYWORDS:}

Popular Culture. Mamulengo's Theatre. Childhood. Play. Music.

Palabras clave: Cultura Popular. Teatro de Mamulengo. Infancia. Juego. Música. 


\section{QUAL A GRAÇA DO MAMULENGO?}

HÁ MUITo que as manifestações dramáticas da Cultura Popular vivenciam um conflito entre a tradição e a contemporaneidade, entre as suas necessidades de permanência e de reinvenção. Em que pese os teóricos dos estudos culturais (GARCÍA CANCLINI, 2013; HALL, 2000) e historiadores da cultura (BURKE, 2010) já terem superado esse embate, ele ainda é presente no processo criativo de artistas e produtores de Cultura Popular. Debates, queixas, perdas e ganhos, dores e alegrias, dúvidas e certezas permanecem na lida produtiva dos brincantes. Qual o limite entre as condições de permanência e de renovação dessas expressões culturais? A interação dos artistas populares com o mercado de bens culturais, com o público, com diferentes espaços de apresentação e com manifestações cênicas contemporâneas interfere nos modos de produção desses artistas? De que maneira as tramas que se articulam na cultura urbana, suas convergências, choques e intercâmbios influenciam a arte popular na atualidade?

Para se pensar sobre as intercorrências da tradição na contemporaneidade, há que se levar em conta duas categorias: o tempo e o espaço. Por um lado, o deslocamento para o universo urbano de temas e formas que remontam ao universo rural; por outro, a operação de rememorar narrativas e linguagens de longa tradição. 
Pesquiso Teatro de Mamulengo desde 2014. Grande parte dos dados e reflexões aqui apresentados foi colhida em depoimentos e no acompanhamento de apresentações de bonequeiros pelo Rio Grande do Norte (RN) ao longo dos últimos cinco anos. Também destaco para estas conclusões minha participação no V, VI e VII Encontro de Bonecos e Bonequeiros do Teatro de João Redondo do RN, realizado pela Fundação José Bezerra em parceria com a Associação Potiguar de Teatro de Bonecos no município de Currais Novos/RN, entre setembro e outubro dos anos de 2017, 2018 e 2019. O evento reuniu, a cada edição, cerca de 20 mamulengueiros do Estado.

As performances do Encontro se deram em escolas desse município e num grande teatro de arena de alvenaria, estabelecido na Praça Tetê Salustino, no Centro da cidade. Somente nas apresentações noturnas, o evento apresentou uma média de seis mamulengueiros a cada noite, durante as quais a arquibancada lotava rapidamente e assim permanecia até antes da última função acabar. Mesmo competindo com outras opções de lazer noturno: bares, show de forró, lanchonetes, o envolvimento da população de Currais Novos com as apresentações foi tamanho que me fez refletir sobre o que manteria o interesse de tanta gente, de diferentes faixas etárias, no Teatro de Mamulengo.

Também saliento para essa análise a apresentação feita por Mestre Felipe de Riachuelo e por Heraldo Lins em 24 de junho de 2018, noite de São João, no Bar do Zuza, município de Riachuelo/RN. Essa brincadeira inseriu-se no projeto de circulação organizado pelo bonequeiro Heraldo para o seu espetáculo Show de Mamulengo, contemplado pelo Edital de Seleção Pública para Culturas Populares Edição Leandro Gomes de Barros de 2017, do Ministério da Cultura (MEC). Essa foi uma função sui generis, uma vez que o Bar do Zuza fica nas imediações do Sítio Lagoa do Sapo, no distrito da Serra da Melosa, zona rural de Riachuelo. As barracas de mamulengo de ambos os mestres foram armadas no alpendre do bar e o público era formado por moradores do distrito, crianças e adultos.

Nesse espetáculo da Serra da Melosa, inicialmente, os moradores se deslocaram até o bar para comerem quitutes, beberem e até, em alguns casos, jantaram, como fazem de costume nos finais de semana. O Bar do Zuza funciona como um ponto de lazer do distrito, à beira de uma estrada de terra e em meio a fazendas. 
Quando já havia cerca de mais de 100 pessoas agrupadas no grande terreno da bodega, a se alimentar, beber e ouvir música, é que os brincantes começaram sua função. O evento também foi singular uma vez que juntou no mesmo programa um calungueiro da capital, Heraldo Lins, e outro do interior, Mestre Felipe de Riachuelo.

Um dos fatos mais notáveis nas dezenas de funções que tenho acompanhado ao longo dessa trajetória de pesquisa é o quanto o teatro de bonecos popular do Nordeste ainda é eficiente como forma de espetáculo cômico-popular. Por eficiente, entendemos aquilo que "se caracteriza pelo poder de produzir um efeito real" (EFICIENTE, 2001, p. 1102) e concreto. Esse efeito, neste caso, é o riso.

Essa capacidade do Teatro de Mamulengo de fazer os espectadores rirem se dá tanto diante de plateias infantis quanto de adultas, seja no Sudeste quanto no Nordeste. É notório o quanto duas ou três cabeças esculpidas em pau, a cada cena movimentando-se e falando, prendem a atenção e levam ao riso as plateias das mais variadas classes sociais, níveis culturais e faixas etárias. Como um brincante, no século XXI, consegue manter a atenção do público e extrair a gargalhada de dentro de uma barraca de tecido rústico e com alguns bonecos de madeira? A pergunta que mais me instigava no começo da pesquisa era: qual é a graça do Mamulengo?

Num mundo cada vez mais dominado pelas fontes de entretenimento com alto nível tecnológico (games, filmes, entre outros), oferecidas em casas de jogos, computadores, tablets, celulares e via internet, haveria espaço para uma forma de diversão como o teatro de bonecos popular? Afinal, as formas de apresentação desse gênero de títeres são remotas. Remetem, na sua origem, à Idade Antiga. Mais especificamente, em relação ao Teatro de Mamulengo brasileiro, trata-se de uma forma de teatro animado que data de, pelo menos, o século XIX.

O teatro de bonecos popular do Nordeste empreendido hoje não é o mesmo daquele registrado nos jornais do século XIX. (BORBA FILHO, 1968) Os escassos e enxutos registros que mencionam essa expressão popular, se comparados ao Teatro de Mamulengo que se produz hoje em dia, dão conta das modificações que o brinquedo sofreu ao longo do último século. Da mesma maneira, podemos 
inferir que o teatro de fantoches utilizado pelos jesuítas no período colonial como instrumento de catequização (MOURA 2000) - a mais provável fonte de influência para o desenvolvimento desse teatro no Brasil, também não era igual aos espetáculos relatados pelos textos de viajantes e jornalistas do século XIX.

Mesmo assim, apesar de suas transformações, existe um núcleo de elementos, de forma e conteúdo, pouco alterado ao longo dos tempos na brincadeira. ${ }^{2}$ Esses elementos, quase permanentes, contemplam:

1. os temas e personagens das fábulas: alusivos ao cotidiano das classes sociais populares, sobretudo rurais;

2. o suporte de apresentação: uma tolda revestida de pano;

3. as técnicas de manipulação: bonecos de luva e vara, algumas vezes com articulações.

2 Denominação de uma apresentação de teatro de bonecos popular nordestino. Por extensão, brincante é o titeriteiro e brinquedo o conjunto de equipamentos utilizado para uma apresentação.

3 As formas de transmissão da brincadeira começaram a se alterar nos últimos anos. Para maiores detalhes sobre processos de transmissão Ver: Macedo (2019) e Carrico (2016).

Podemos entender, portanto, que a base da estrutura dramática e os elementos técnicos de representação e publicação do brinquedo pouco se alteraram. E é nesse tripé que reside a tradição desse teatro; em seu repertório de procedimentos técnicos e códigos cênicos transmitidos até há pouco tempo via mestre-aprendiz. ${ }^{3}$

A grande questão que se nos apresenta, como pesquisadores do Teatro de Mamulengo, é pensar se, apesar da vinculação a essa tradição, ele ainda se comunica com o público do século XIX, se ele ainda funciona como gênero de teatro de formas animadas. A hipótese que aqui tentamos apresentar é a de que existe um tríptico de elementos que mantém o Teatro de Mamulengo efervescente e eficiente enquanto gênero de teatro popular. Seriam eles: uma estética ao mesmo tempo infantil e adulta, o jogo e a música; ou seja, a dialética entre aspectos simbólicos infantis e adultos, a sua dimensão lúdica e a sua incorporação da expressão musical como componente essencial de dramaturgia. 


\section{PRIMEIRA GRAÇA: INFÂNCIA ADULTA}

Na maior parte das cidades nas quais acompanhei o Teatro de Bonecos Popular Nordestino desde meu pós-doutorado - São Paulo, Campinas, Piracicaba, Natal, Olinda, Currais Novos, Macau, Caicó, Riachuelo, Carnaúba dos Dantas - as apresentações não se dão por iniciativa do brincante, mas são organizadas por instituições culturais - SESC, SESI, escolas, secretarias de cultura estatais, fundações culturais. O público dos eventos organizados por essas entidades reage à brincadeira do mesmo jeito que o público do sítio?

Uma das questões em relação a esse contexto de difusão do Mamulengo é que nele grande parte da plateia é formada por crianças. Isso talvez se deva em razão do horário dessas funções que na cidade, geralmente, não são levadas à noite, como no sítio, mas durante o dia. E geralmente nos finais de semana, quando os parques, praças e espaços de cena dessas organizações culturais são frequentados eminentemente por famílias. Ou talvez porque o público por si mesmo associe o boneco com a infância. Afinal, em todo o mundo existe uma antiga tendência de relacionar o teatro de fantoches ao público infantil. E com o teatro de bonecos nordestino isso não é diferente.

Registros publicados de pesquisadores brasileiros de diferentes épocas (BORBA FILHO, 1966; GURGEL, 2008; SANTOS, 1979) e relatos orais dos brincantes por mim entrevistados - Heraldo Lins, Felipe de Riachuelo, Raul do Mamulengo - dão conta de que, antigamente, o Mamulengo era muito mais malicioso. Percebemos que hoje ele está se adaptando aos padrões de linguagem e representação politicamente correta para se adequarem à recepção infantil. Um exemplo dessa adaptação diz respeito às cenas de lutas com armas e a utilização de palavrões que, outrora frequentes, hoje são raras.

Em que pese o sarcasmo e a malícia do texto, alicerçado sobre trocadilhos, jogos verbais e regionalismos, não vi esse tipo de apelo nas brincadeiras que acompanhei. Com exceção de Edicharles Bezerra (RN), Gilberto Calungueiro (CE) e Augusto Bonequeiro (CE) não registrei nenhum brincante utilizando palavrão. Raul do Mamulengo (RN) e Felipe de Riachuelo (RN), ainda que algumas vezes 
representem negros, gays e mulheres de uma forma que atualmente pode ser considerada preconceituosa, também cuidam de seu vocabulário. Podemos afirmar que, no contexto da cultura urbana, de maneira geral, o Mamulengo ficou bem-comportado, politicamente correto. Heraldo Lins e Emanuel Amaral, artistas de Natal, declaram ter "higienizado" suas brincadeiras na última década, para atenderem à demanda de contratações de escolas e entidades.

Apesar de apresentar alguns tipos míticos ou figuras de animais, os personagens-tipo do Mamulengo não são crianças. Os bonecos de Felipe de Riachuelo, Raul do Mamulengo e Edicharles Bezerra são adultos vivenciando situações da vida adulta: adultério, jogos de sedução, disputas de valentia, exploração religiosa, busca por saúde, dinheiro, dificuldades com a vida e, sobretudo, exploração no trabalho.

Mesmo com esses temas e personagens, no contexto das apresentações públicas de Mamulengo em praças e teatros de metrópoles, é notável um espírito de nostalgia na audiência. Em Natal, por exemplo, alguns espectadores, inclusive natalenses que migraram do interior para a capital, declararam em seus depoimentos que o brinquedo os faz lembrar da infância ou da cidade de origem. Para eles, compor uma plateia compactuando com o riso das crianças é como fazer uma viagem no tempo e no espaço. Esse despertar da memória de uma bucólica terra natal, um passado idílico e uma infância “perdida” talvez também contribua para o interesse do adulto na brincadeira.

Afinal, a Cultura Popular compartilha dos mesmos signos essencialistas frequentemente associados ao conceito de infância, tais como pureza, inocência, autenticidade e criatividade. (BURKE, 2010) Dadas as atribuições remotas e campestres geralmente atribuídas a essa cultura, sua expressão vem sempre acompanhada dessa simbologia.

Um bumba-meu-boi, por exemplo, não é hoje, nem para nós nem para os que dele participam diretamente, o que foi há cinquenta anos, tal como o descreveram e interpretaram Mário de Andrade, Ascenso Ferreira ou Hermilo Borba Filho. E certamente haverá de ser outra coisa daqui a cinquenta anos, se continuar existindo até então. De qualquer forma, continua sendo um símbolo 
privilegiado para que pensemos, a partir dele, questões de identi-

dade nacional e regional, integração comunitária, conflitos sociais e políticos, estética, religiosidade, tecnologia, vida, etc. É essa abertura do símbolo, justamente por permanecer presente, o que se ganha com a tradição e que se perde com a amnésia intencional de formas massificadas que se recusam a fixar-se no tempo. (CARVALHO, 1987, p. 19)

Nesse contexto, é possível que o palavrão e o deboche "maculem" a leveza desses símbolos associados pelo senso comum ao popular. Paradoxalmente, é a malícia um dos elementos que mais desperta o riso nos adultos. E quem sabe pudéssemos considerar justamente a picardia como outra das graças do Mamulengo. Juntos, crianças e adultos, querem rir o mesmo riso. $\mathrm{O}$ adulto quer se associar ao universo infantil, sobretudo, se estiver acompanhando um infante na brincadeira. A criança quer rir das piadas cujo conteúdo, muitas vezes, não entende completamente. Para ela, desfrutar do humor adulto é uma maneira de se sentir mais velha.

É discutível até que ponto a patifaria do boneco - presente em outros gêneros dito infantis, como a palhaçaria - estraga a atmosfera infantil instaurada pela brincadeira. A sacanagem do Mamulengo daria à garotada licença para ouvir "conversa de adulto"? Ou a imagem pueril de bonecos e bichos a brincar e dançar permitiria ao adulto transportar-se para seu próprio universo infantil? Talvez essa singular conjunção abra um terceiro campo, adulto e infantil ao mesmo tempo, a transcender essas duas classificações. Um campo que na sua dialética se constitui simultaneamente divertido tanto para os pequenos quanto para os maiores. A esse campo simbólico denominei de infância adulta.

É importante considerar que a época em que se deu a consolidação formal do teatro de bonecos popular do Nordeste, o século XIX, era um período em que o conceito de infância era distinto do atual e os limites de separação entre vida adulta e infância eram muito mais sutis. Foi dentro desse contexto que se desenvolveu a arte do Mamulengo. Ela é anterior à divisão do teatro em faixa etária: teatro infantil $X$ teatro adulto. Essa é uma divisão comercial e moral feita pela sociedade urbana, burguesa, a partir do século XX. 
Independentemente das discussões acerca da orientação etária desse gênero teatral, ressalto nessa problemática o quanto a participação comum de meninas, meninos e adultos em uma mesma brincadeira pode ser um dos indícios de seu vigor e permanência.

\section{SEGUNDA GRAÇA: O JOGO}

Partimos do pressuposto de que o Mamulengo, por ser uma arte teatral, é um jogo. E enquanto jogo está delimitado por dois fatores: um campo (a empanada na qual os bonecos se movimentam) e uma fração de tempo. (HUIZINGA, 1997) Sua duração é proporcional à satisfação da plateia, sendo feito para rir e alegrar. Uma função programada, às vezes, para durar meia hora pode se encerrar em 15 minutos. É preciso que não seja tão rápido a ponto de não conseguir fisgar a empatia dos auditores, mas que, ao mesmo tempo, não se demore a ponto de cansá-los. Aqui o conceito de "breve" e "longo" é relativo e varia de acordo com a audiência. Raul do Mamulengo, Emanuel Bonequeiro e Emanuel Amaral afirmam em seus depoimentos ser impossível prever o grau de envolvimento do público antes dos fantoches despontarem no biombo. Percebemos no trabalho desses três brincantes que a duração de uma brincadeira depende da percepção desse envolvimento - e o difícil domínio desse tempo é uma de suas principais habilidades.

Em geral, pode-se pensar que o público da zona rural e do interior tem mais familiaridade e, portanto, predisposição ao brinquedo e que o da capital exigiria uma performance mais ligeira. Mas isso também não é regra. Na Serra da Melosa, no agreste potiguar, por exemplo, mesmo nas casas de taipa e sem encanamento, os postes de wi-fi das redondezas possibilitam que os adolescentes e adultos acessem a internet - principal fonte de lazer. Nesses ambientes agrários vimos como, muitas vezes, sobretudo entre os jovens, o Mamulengo pode não despertar tanto interesse. Havia pessoas no Bar do Zuza que estavam envolvidas com 
a brincadeira de Mestre Felipe de Riachuelo enquanto outras eram entretidas com jogos no aparelho celular.

Já em Natal, por exemplo, presenciamos uma brincadeira de Heraldo Lins no Parque das Dunas que durou mais de 20 minutos, encerrada sob a ovação das crianças, debaixo de palmas e pedidos para continuar.

O brincante compete com toda a sorte de distrações que circundam uma apresentação de teatro de rua: motores e buzinas do trânsito, movimentação de transeuntes, carros de som e anúncios eventuais. Como se já não bastasse a energia despendida por todo o ator para concentrar o olhar da audiência na sua pequena caixa, essa concorrência duplica o empenho do bonequeiro popular em manter a atenção da plateia.

Quando a apresentação se dá em locais públicos, de espaço amplo, como as que acompanhamos na feira livre de Currais Novos em 2017, 2018 e 2019, uma função de Mamulengo conta, invariavelmente, com a presença de um ou mais moradores de rua. Esses moradores, muitas vezes em condição de desequilíbrio mental ou bêbados, participam das brincadeiras: conversam com os bonecos, respondem aos chamamentos do brincante, dançam as músicas, cantam e, às vezes, se aproximam da tolda para tocarem nos títeres.

Numa apresentação desse tipo é preciso então que a atenção do ator-bonequeiro se divida em três níveis. No primeiro nível, o mais imediato, ele deve focar na fábula que desenvolve com seus mamulengos. No segundo nível, no interesse e na reação do público. No terceiro, nas sucessivas intercorrências do ambiente externo, simultâneas ao momento da apresentação e carregadas de estímulos que podem desviar a atenção da audiência.

A dimensão lúdica do Mamulengo se estabelece principalmente a partir da operação que o brincante desenvolve com o segundo e o terceiro nível. Muitos calungueiros extraem graça muito mais daquilo que está à volta da barraca de pano do que das piadas e situações vividas por suas criaturas de madeira. Esses são os que fazem mais sucesso. 
Em relação ao terceiro nível, é fundamental que o ator saiba quais ocorrências do ambiente vai aproveitar para sua brincadeira, reagindo a elas, e quais vai desprezar. Se interromper a fábula para responder aos frequentes estímulos ambientais do espaço público, perde o fluxo narrativo, enfraquece o ritmo do espetáculo e arrisca perder o entusiasmo dos espectadores. Por outro lado, improvisar uma piada em cima de um transeunte distraído, de uma sirene de ambulância ou de um grito perdido no largo desperta a gargalhada e fortalece a relação de empatia entre manipulador-espectador.

Para Emanuel Bonequeiro (Emanuel Anderson de Souto Veríssimo), 31 anos, jovem brincante do município de Caicó/RN, existe uma diferença entre o improviso e o imprevisto. Segundo seu depoimento, todo imprevisto pode gerar o improviso, mas nem todo o improviso é imprevisto:

\begin{abstract}
Improviso é quando a plateiajoga um tema para o bonequeiro e ele começa a desenvolver. Isso se chama improviso [...] O acaso, por exemplo, como eu vou muito para a feira... de repente, você tá no meio da feira e entra (sic) cinco pessoas gritando ao mesmo tempo. E você tem que lidar pra que essa situação não gere desconforto em quem está assistindo e nem perca o sentido da história. ${ }^{4}$
\end{abstract}

Para ele, o imprevisto propõe um começo, mas o fim depende do jogo-de-cintura do ator. Emanuel entende que o calungueiro experiente dispõe de um repertório de gags, efeitos de manipulação e piadas. Esse repertório, que ele denomina de “improviso”, seria formado por códigos cênicos pré-ensaiados e por situações de improviso que, uma vez experimentadas em cena, vão se juntando a esse acervo. Para ele, de nada adianta o mamulengueiro lançar mão dessas fórmulas se não souber adequar sua aplicação às contingências acidentais de cada apresentação.

"Por isso o improviso pode ser repetido, já o imprevisto não se repete", afirma. Outra diferença entre improviso e acaso, no jogo cênico do boneco popular, é que o improviso é estabelecido pelo brincante, já o acaso é dado pelas circunstâncias. E é a proporção entre o que acontece ao acaso e a capacidade do brincante de improvisar soluções ad hoc que desperta e mantém o interesse da plateia.
4 O depoimento foi concedido a André Carrico, em 28 agosto de 2018. 
Existe ainda uma dicotomia que pode acompanhar e fortalecer a dimensão lúdica da brincadeira de Mamulengo. Ela se dá entre a dramaturgia verbal e a dramaturgia do corpo. Ou entre a comicidade de texto e a comicidade visual do espetáculo. Nesse caso, por dramaturgia verbal entendemos o encadeamento da fábula a partir dos diálogos entre os personagens-tipo e os solilóquios do brincante. Por dramaturgia visual, indicamos o desenvolvimento narrativo a partir dos movimentos dos fantoches e de eventuais objetos de cena.

Desse modo, podemos pensar numa dramaturgia daquilo que é visto em cena pelo público, mas que é animado pela movimentação corporal do brincante, camuflado por trás da tolda. Assim, teremos uma correlação lúdica entre o que é dito pelos mamulengos e o gesto ou movimento que estes desempenham. A coerência ou incoerência dessa correlação entre corpo e palavra, movimento e fala, reforça a dimensão lúdica do Mamulengo.

No Rio Grande do Norte, por exemplo, a palavra ocupa muito mais espaço na ação cênica do que no teatro de bonecos de outros Estados. Essa característica de verborragia foi encontrada na brincadeira dos titeriteiros Heraldo Lins, Emanuel Amaral, Edicharles de Macau, Felipe de Riachuelo, Aldenir Dantas, Raul do Mamulengo, Francisquinho de Passa-e-Fica e Emanuel Bonequeiro. Muitos desses brincantes norteriograndenses apresentam passagens inteiras em que seus bonecos aparecem na empanada apenas para contar piada. Edicharles de Macau e Heraldo Lins, por exemplo, afirmam ter aprendido suas piadas com palhaços de circo.

Se comparados aos bonequeiros de Pernambuco e de São Paulo, como Zé de Vina, Zé Lopes e Valdeck de Garanhuns, suas funções são muito mais parlapatonas. Tendo já acompanhado a brincadeira de mais de 40 brincantes nordestinos, sendo 29 brincantes potiguares, ${ }^{5}$ sete pernambucanos (alguns atuando em São Paulo $^{6}$ e quatro cearenses ${ }^{7}$ registramos que, na comparação, o brinquedo pernambucano valoriza mais os aspectos plásticos-visuais. Entre esses aspectos, destacamos a quantidade de objetos de cena, o detalhamento na decoração das empanadas e nos detalhes dos bonecos, a eventual utilização de maquetes de igrejas e casas ou telas de fundo como cenário. Sem querer estabelecer regras definitivas, pois há exceções, ${ }^{8}$ reparamos que, nos brincantes de João Redondo por nós pesquisado os detalhes visuais e ornamentos são menos recorrentes.

5 Mestre Raul do Mamulengo, Heraldo Lins, Caçuá de Mamulengo (Ronaldo e Naldinho), Mestre Felipe de Riachuelo, Emanuel, Luciana e Gabriel Amaral, Mestre Francisquinho de Passae-Fica, Antônio Alisson, Genildo Mateus, Shicó do Mamulengo, Emanuel Bonequeiro, Edicharles Bezerra, Ricardo Guti, Catarina Calungueira, Daniel de Chico Daniel, Josivan de Daniel, Tio João da Quadrilha, João Viana, Mestra Dadi, Aldenir Dantas, Mané de Dadica, Marcelino de Zé Limão, Geraldo Maia, Zé Fernandes, Manoel Messias, Os Galantes (Erinaldo e Zildalte Macêdo).

6 Zé de Vina, Zé Lopes, Cia Mamulengando Alegria, Mestre Saúba, Valdeck de Garanhuns, Danilo Cavalcanti e Sandro Roberto.

7 Gilberto Calungueiro, Augusto Bonequeiro, Epidemia de Bonecos (Isabel e Cláudio Magalhães).

8 São exceções os brinquedos de Heraldo Lins, Raul do Mamulengo, Shicó do Mamulengo e Emanuel Amaral; quatro brincantes potiguares que primam pelo acabamento e pelos detalhes ornamentais em seus mamulengos, adereços e toldas. 


\section{TERCEIRA GRAÇA: A MÚSICA}

Ao longo de sua trajetória, o Teatro de João Redondo incorporou em sua poética recursos de outras expressões culturais nordestinas: a Literatura de Cordel, as Artes Visuais, o Artesanato, as Danças Dramáticas, a Música. A última é de todas as expressões acima citadas a mais importante. Assim como na dramaturgia de outras manifestações dramáticas da Cultura Popular brasileira, a música desempenha função basilar no Mamulengo.

Marchas, xotes, baiões, cocos, frevos e trotes são os principais ritmos executados durante uma brincadeira de títere nordestino, ao vivo ou em gravações mecânicas. São eles a sugerir os matizes dramáticos da fábula, dando a ambientação de cada entrecho. Um baile se anuncia por marcha ou baião, uma boneca sensual pode entrar dançado xote, um personagem prolixo puxa um repente em ritmo de coco e assim por diante. Há manipuladores que extraem graça da dança de seus fantoches, na maneira como articulam suas mãos e cabeças, fazendo-os acompanhar esses ritmos.

Ressalta-se aqui a vantagem dos mestres que trabalham com seus próprios músicos e que podem, ao longo do tempo, estabelecer com os mesmos códigos que fortaleçam essa relação de reciprocidade. Pois a música também se encarrega da administração do ritmo cênico, ao encadear as cenas do espetáculo, como se fosse uma ópera popular. Além disso, frequentemente, ela convida a plateia a dançar.

Podemos entender a música ainda como elemento formal que dá suporte à outra graça do brinquedo que é a sua dimensão lúdica. Por se tratar de um jogo improvisado, ela pode servir para tapar buracos, como no caso do titeriteiro atrasar a entrada de um mamulengo ou mesmo se perder em seus diálogos e loas. É comum ouvir o brincante pedir antes de baixar os bonecos para encerrar uma passagem: “Arrocha o fole sanfoneiro!". Vemos a tolda vazia e o espetáculo preenchido apenas pelo som da música.

A música também pode ter função narrativa na brincadeira. As loas cantadas pelos brincantes são canções específicas desenvolvidas ao longo de décadas pelos 
mestres e que compõem um repertório próprio. Trata-se de células melódicas curtas cujas letras são elogiosas ou de escárnio e que, em alguns casos, podem ser apenas recitadas, como poemas. Entoadas antes da entrada dos principais personagens-tipo, elas servem para apresentá-los e como referência na indicação da cena a seguir. Assim, no João Redondo, por exemplo, cada boneco importante - Baltazar, João Redondo, Quitéria, o Boi - tem a sua própria canção. Algumas são temas originais, outras, adaptações ou paródias de canções do repertório tradicional nordestino.

Os baiões e xotes também podem servir para promover um breve descanso nos braços do brincante e permitir a troca de bonecos. Em seguida, brecar a execução musical serve para recuperar a atenção do espectador e redirecioná-la para o texto, para a compreensão das situações e piadas.

No Rio Grande do Norte, a maioria dos brincantes emprega a música como ambientação ou nas passagens coreográficas, em que os mamulengos entram apenas para dançar. Dos manipuladores que acompanhamos em pesquisa de campo, apenas Heraldo Lins e Ricardo Guti exploraram a função narrativa da música, aproveitando loas recolhidas com seus velhos mestres, como Bastos, Chico Daniel e Chico Simões, ou composições próprias, para apresentarem situações ou personagens-tipo. Heraldo tem formação técnica em música, já foi professor de violão e proprietário de uma escola de música. Talvez por isso dê tanto destaque à ambientação musical. É comum, por exemplo, em suas apresentações, ver-se o público aproveitar a música mecânica ou mesmo o trio de forró para dançar, tanto antes da brincadeira começar quanto depois. Ricardo Guti compõe e parte do seu repertório é formado por material criado exclusivamente para sua brincadeira.

Numa apresentação de Mamulengo na rua é comum que, antes da função ter início, a música já comece a ser executada; seja em gravação mecânica ou seja por um trio de forró ao vivo. Incluímos a música como uma das graças do teatro de bonecos popular porque percebemos que esse aquecimento antes dos bonecos aparecerem é o principal chamariz que atrai o público para a tolda. Antes mesmo que a fábula seja posta em marcha, muita gente já está diante da barraca: ouvindo os músicos, cantando junto, dançando ou simplesmente esperando que algo suceda àquele prenúncio promissor. Certamente ela é um dos elementos primordiais da brincadeira. 


\section{CONSIDERAÇÕES FINAIS}

Apesar de seguir um repertório de convenções gestado ao longo de décadas por uma tradição (temas, motivos, esquemas), um mamulengueiro não se atém apenas a esses recursos, inventando e incorporando tudo aquilo que estimule o riso e a participação direta da plateia. No século XXI, ao se estabelecer em outros territórios, brincando com outros públicos e diante de novas formas de recepção, o Teatro de Mamulengo entra em processo de hibridização e seus artífices devem se articular com o campo de códigos e discursos heterogêneos do mundo contemporâneo, digital e globalizado. Nesse contexto, procuramos problematizar o que mantém o interesse de uma parcela significativa de público, de diferentes faixas etárias, nessa remota expressão teatral.

Ao acompanhar o trabalho de brincantes ao longo dos últimos anos, temos percebido o quanto sua graça ainda é eficiente. Consideramos como demonstrações de eficácia de comunicação do brinquedo as seguintes constatações:

a. O comparecimento de grande número de espectadores em apresentações em praça pública (nas cidades de Currais Novos/RN, Caicó/RN e Carnaúba dos Dantas/RN, por exemplo), mesmo competindo com outras opções simultâneas de lazer noturno: lanchonetes, shows de forró, eventos esportivos;

b. O envolvimento dos espectadores, adultos e crianças, na participação entusiástica e permanente do espetáculo, dialogando com os bonecos e rindo muito;

c. A permanência predominante da plateia durante as funções, acompanhando-as até o final.

Um dos elementos que mais desperta o riso do Mamulengo, sobretudo nos adultos, é a malícia. E quem sabe pudéssemos considerar justamente o deboche como outra das graças do brinquedo. Outro possível fator a favorecer a graça desse gênero é a sua linguagem multifacetada e híbrida. Afinal, ao longo de sua 
existência, o teatro de bonecos popular acabou tornando-se uma esponja cultural, cuja linguagem reúne elementos do cancioneiro popular nordestino, das Danças Dramáticas, do Artesanato, da Literatura de Cordel, entre outros. Assim sendo, o Mamulengo é um resumo das principais vertentes da Cultura Popular Nordestina.

Mas, apesar da existência de diversos elementos relevantes para a permanência do Teatro de Mamulengo enquanto gênero cômico-popular, aqui ressaltamos três aspectos: a instauração de um espaço ambíguo, que chamamos de infância adulta - e dentro dele, de uma estética correlata; a dimensão lúdica e a participação da música.

Em relação ao que denominamos de infância adulta, trata-se da instauração de um campo simbólico que é adulto e infantil, ao mesmo tempo, divertindo pequenos e maiores. Nos parece que, ao assistirem a uma função de Mamulengo, crianças e adultos, juntos, querem rir o mesmo riso. Nessa operação, o adulto quer se associar ao universo infantil, sobretudo, se estiver acompanhando de uma ou mais crianças durante a audiência. Enquanto o adulto se permitiria vivenciar uma expressão de nostalgia da própria infância, a criança encontraria um espaço livre para acompanhar personagens e situações da ansiada vida adulta, entendendo suas piadas e demonstrando esse entendimento através da risada compartilhada.

Sobre a natureza de jogo de uma encenação de títere popular, ela é dada devido à sua condição de arte que se faz em cima da interação com a plateia: o brincante desenvolve sua apresentação a partir do que dela recebe. Para isso, se fazem necessários a atenção, a prontidão e o diálogo com as sucessivas intercorrências do ambiente externo à função. No João Redondo, o enredo é apenas pretexto para a instauração de uma brincadeira. O imprevisto da hora propõe apenas um começo, mas o fim depende do jogo-de-cintura do atuante. A capacidade de improviso do mamulengueiro advém da recorrência a um repertório próprio e ensaiado de gags, efeitos de manipulação e piadas.

A participação da música, enquanto peça fundamental para a realização de um espetáculo de Mamulengo, é a terceira graça aqui destacada. As funções da música na brincadeira são: atrair público para a barraca, criar a ambientação das cenas, administrar o ritmo cênico, dar suporte para as cenas de dança de fantoches 
- convidando inclusive, eventualmente, a plateia a dançar - e oferecer um breve descanso aos braços do brincante entre uma passagem e outra. A música também pode, em alguns casos, servir para tapar buracos do espetáculo, como no caso de o brincante atrasar a entrada de um mamulengo ou mesmo se perder em seus diálogos. Em outros casos, pode ainda assumir função narrativa por meio da execução de loas, canções específicas que descrevem personagens-tipo e situações.

Todos os apontamentos aqui apresentados são reflexões iniciais, indicações de caminhos, hipóteses preliminares. Cada um dos elementos da brincadeira popular aqui destacados requer maior desenvolvimento e aprofundamento. O propósito de nosso artigo é despertar uma possibilidade de reflexão.

Destacamos o apelo dessas três graças para a vitalidade da brincadeira; mas isso não significa que sejam as únicas. O Teatro de Bonecos Popular do Nordeste não se esgota nesses três elementos. Ele é uma arte de múltiplos apelos e de tantas outras graças.

\section{REFERÊNCIAS}

BORBA FILHO, H. Fisionomia e espírito do mamulengo. São Paulo: Nacional, 1966.

BURKE, P. Cultura popular na Idade Moderna: Europa 1500-1800. São Paulo: Companhia das Letras, 2010.

CARVALHO, J. J. As duas faces da tradição. In: REUNIÃO INTERAMERICANA SOBRE CULTURA POPULAR E TRADICIONAL, 2., 1987, Caracas. Anais [...]. Caracas: [s. n.], 1987. p. 2.

EFICIENTE. In: HOUAISS, A. Dicionário Houaiss da Língua Portuguesa. Rio de Janeiro: Objetiva, 2001

GARCÍA CANCLINI, N. Culturas híbridas: estratégias para entrar e sair da modernidade. São Paulo: EdUSP, 2013.

GURGEL, D. O reinado de Baltazar: teatro de João Redondo. Natal: Fundação Capitania das Artes, 2008.

HALL, S. A identidade cultural na pós-modernidade. 4. ed. Rio de Janeiro: DP\&A, 2000.

HUIZINGA, J. Homo Ludens. São Paulo: Perspectiva, 2007. 
MACEDO, Z. R. Teatro de João Redondo do Rio Grande do Norte: transmissão, negociação e

circulação da prática e do saber. 2019. Tese (Doutorado em Antropologia) - Centro de Ciências Humanas, Letras e Artes, Universidade Federal do Rio Grande do Norte, Natal, 2019.

MOURA, C. F. M. Teatro a bordo de naus portuguesas nos séculos XV, XVI, XVII e XVIII. Rio de Janeiro: Instituto Luso-Brasileiro de História - Liceu Literário Português, 2000.

SANTOS, F. A. G. Mamulengo, um povo em forma de boneco. Rio de Janeiro: Funarte, 1979.

AndRÉ CaRrico: é doutor e mestre em Artes (Teatro) pela Universidade Estadual de Campinas (Unicamp), com pós-doutorado em Artes da Cena. Professor adjunto do curso de Teatro da Universidade Federal do Rio Grande do Norte (UFRN) e do Programa de Pós-Graduação em Artes Cênicas (PPGArC). 